CONGENITAL HEART DISEASE

\title{
Coagulation profile and liver function in 102 patients after total cavopulmonary connection at mid term follow up
}

\author{
V Chaloupecký, I Svobodová, I Hadačová, V Tomek, B Hučín, T Tláskal, J Janoušek, O Reich, \\ J Škovránek
}

See end of article for authors' affiliations

.....................

Correspondence to: Dr V Chaloupecký, Kardiocentrum, University Hospital Motol, $V$ úvalu 84,15006 Prague 5, Czech Republic; vaclav.chaloupecky@ Ifmotol.cuni.cz

Accepted 31 March 2004

\begin{abstract}
Objective: To examine coagulation factors and liver function test abnormalities in patients after total cavopulmonary connection (TCPC).

Design: Cross sectional study comprising clinical and echocardiographic evaluation, and biochemical and coagulation profile screening.

Setting: Tertiary referral centre.

Methods: 102 patients aged 4-24 years (median 10 years) at one to eight years (median five years) after TCPC were examined. All patients were maintained on a low dose of aspirin. $96 \%$ of patients were in a good clinical condition (New York Heart Association class I or II). No intracardiac thrombi were detected on echocardiography and ventricular function was good in $91 \%$ of patients.

Results: Total bilirubin was increased in $27 \%$ and $\gamma$ glutamyltransferase in $54 \%$ of patients. Serum total protein, albumin, and prealbumin were normal in almost in all patients. Compared with the control group, patients after TCPC had significantly lower fibrinogen, factor V, factor VII, and protein C concentrations, prolonged international normalised ratio, and increased antithrombin III concentration. Factor V concentration was abnormally decreased in $35 \%$, factor $\mathrm{VII}$ in $16 \%$, and protein $\mathrm{C}$ in $28 \%$ of patients. Antithrombin III was increased in $23 \%$ of patients. Factor VII, factor V, protein C, and antithrombin III correlated significantly with serum prealbumin. There was also a significant correlation between procoagulant factor VII and both anticoagulant protein $\mathrm{C}$ and antithrombin III.

Conclusions: Almost half of patients after TCPC had laboratory signs of mild cholestasis. Decreased liver synthesis of procoagulant and anticoagulant factors was observed but overall coagulation homeostasis appeared to be in balance in this selected group of patients with a good clinical outcome.
\end{abstract}

$\mathrm{T}$ otal cavopulmonary connection (TCPC) is generally recognised as the best palliation of complex congenital heart defects with functionally single ventricle. In patients followed up after TCPC the average central venous pressure ranged from $10-11 \mathrm{~mm} \mathrm{Hg}^{12}$ - that is, about three to four times higher than the normal right atrial pressure in healthy children. Venous congestion is a known predisposing factor in the development of chronic liver diseases in adults. ${ }^{3}$ Major hepatic dysfunction has been also observed in children with various cardiac diseases, particularly in those with systemic venous congestion and hypoxaemia. ${ }^{4}$ The long term impact of an increased venous pressure on liver function in patients after the Fontan procedure is not known but abnormal liver tests and coagulation factor profile have been noted in several studies. ${ }^{15-13}$ We report the results of biochemical and haematological profile screening in a cross sectional mid term follow up study in a large group of patients with functionally single ventricle after TCPC.

\section{METHODS}

\section{Patients}

Between 25 October 2000 and 12 November 2001 a total 102 patients at least one year after TCPC were entered into a cross sectional single institutional follow up study comprising clinical and echocardiographic evaluation with biochemical and coagulation profile screening. All patients were taking a prophylactic low dose of aspirin. Another 23 patients were taking warfarin and one patient with protein losing enteropathy were excluded from the study. The indications for warfarin in that group were patent fenestration or recent fenestration coil occlusion in 17 patients according to our institutional policy; in three patients previous thromboembolic events nine days, four years, and five years after TCPC while they were taking aspirin; and physician preference in three patients. The study was approved by the ethical committee of the University Hospital Motol.

The age of patients in the study ranged from 4-24 years (median 10 years) and the interval from TCPC ranged from one to eight years (median five years). Table 1 summarises the main anatomical diagnoses. In patients with complex double outlet right ventricle, transposition of the great arteries, or corrected transposition of the great arteries, ventricular hypoplasia or straddling of an atrioventricular valve precluded biventricular repair. Sixty eight patients had dominant left ventricular morphology and 34 patients had dominant right or undetermined ventricular morphology. Dextroisomerism was present in three patients, laevoisomerism in two patients, and situs inversus in two patients.

The age of patients at TCPC performed between April 1993 and May 2000 ranged from 1-19 years (median 5 years). An intracardiac lateral tunnel with polytetrafluoroethylene (PTFE) patch was used in 94 patients and extracardiac tunnel with PTFE tube graft in eight patients. In a subgroup of $35(34 \%)$ patients a fenestration $(3-4 \mathrm{~mm})$ was created. A residual intra-atrial baffle leak was confirmed during follow up by transoesophageal echocardiography or cardiac catheterisation in another five patients. The fenestration was closed with a transcatheter device in 16 patients (Rashkind occluder in nine patients, coil in seven patients) or surgically

Abbreviations: INR, international normalised ratio; NYHA, New York Heart Association; PTFE, polytetrafluoroethylene; TCPC, total cavopulmonary connection 
Table 1 The main diagnoses

\begin{tabular}{lc}
\hline Diagnosis & Number \\
\hline Tricuspid atresia & 33 \\
Double inlet ventricle & 29 \\
Double outlet ventricle & 16 \\
Pulmonary atresia with intact ventricular septum & 7 \\
Complex TGA and VSD & 6 \\
Mitral atresia & 5 \\
Complex corrected TGA and VSD & 2 \\
Others & 4 \\
Total & 102 \\
\hline \multirow{2}{*}{ TGA, transposition of the great arteries; VSD, ventricular septal defect. }
\end{tabular}

in four patients. The fenestration closed spontaneously in another eight patients, eight months to six years (median four years) before the study. The baffle leak was closed surgically in two patients and by transcatheter coil occlusion in one patient, four years before the study. Overall, seven patients had open fenestration and two patients had residual baffle leak during the coagulation study.

\section{Echocardiography}

All patients underwent transthoracic echocardiography, in a cross sectional view and with Doppler scanning and colour flow mapping (System Five, GE Vingmed, Horten, Norway) with a 5.0, 3.5, or $2.5 \mathrm{MHz}$ phased array transducer, during the study. Because of the different anatomical diagnoses the ventricular function was classified only semiquantitatively as good, fair, or poor. Atrioventricular valve regurgitation was assessed semiquantitatively on a four grade scale ( 0 or 1 , none or trivial; 2 , mild; 3 , moderate; 4 , severe).

\section{Coagulation studies}

Blood samples were collected by peripheral venepuncture into $3.8 \%$ trisodium citrate (one part anticoagulant to nine parts blood, Sarstedt tubes). Platelet poor plasma was prepared by centrifugation at $3000 \mathrm{~g}$ for 20 minutes. Activated partial thromboplastin time, prothrombin time expressed as the international normalised ratio (INR), fibrinogen, antithrombin III, and the clotting activity of factor VII were determined immediately. For determination of protein $\mathrm{C}$ concentration and clotting activity of factor $\mathrm{V}$, plasma was aliquoted in polystyrene tubes, stored at $-70^{\circ} \mathrm{C}$, and thawed immediately before testing.

INR, activated partial thromboplastin time, and fibrinogen were determined by conventional methods. Antithrombin III and protein $\mathrm{C}$ concentrations were measured with a chromogenic substrate (Chromogenix, Milan, Italy). A one stage clotting activity of factor $\mathrm{V}$ and factor VII were performed using factor deficient plasma (Helena Laboratories,
Beaumont, Texas, USA). All tests were performed on the Sysmex CA 6000 coagulation analyser.

Because of maturation of the haemostatic system during childhood ${ }^{14}$ the results were compared with an age matched control group of 37 healthy children aged 3-15 years and a group of 18 young adults aged 16-32 years who were admitted for one day minor surgery or were volunteers.

\section{Biochemical analysis}

The standard biochemical tests were carried out on an automatic analyser (Advia 1650, Bayer). The results were compared with age matched normal values.

\section{Calculations and statistics}

The biochemical and haematological values were standardised with respect to age matched control values by subtracting the age specific mean for the control group and by dividing the standard deviation to create a $\mathrm{Z}$ value. The individual biochemical and haematological results were considered abnormal if the $\mathrm{Z}$ value was higher than 2.0 or lower than -2.0 . The differences between the groups were compared by unpaired $t$ test. The relation between two variables was determined by simple linear regression. The data were analysed with the statistical packages SPSS Base 11.01 and Systat 10, SPSS Inc (Chicago, Illinois, USA). Results are expressed as mean (SD). Significance was accepted at $\mathrm{p}<0.05$.

\section{RESULTS}

Patients were generally in a good clinical condition; 96 (96\%) were in New York Heart Association (NYHA) class I or II and four $(4 \%)$ were in class III. The NYHA class was not evaluated for two patients. Thirty two patients were taking digoxin, 21 were taking angiotensin converting enzyme inhibitors, and three patients were treated with furosemide (frusemide). The mean oxygen saturation measured by pulse oximetry was 95 (2)\% in 93 patients without intra-atrial communication and $90(3) \%(p<0.001)$ in nine patients with either open fenestration or with a proven baffle leak.

Ventricular function was assessed echocardiographically as good in $93(91 \%)$ patients, as fair in eight $(8 \%)$, and as poor in one patient. Competent atrioventricular valve or trivial atrioventricular valve regurgitation was confirmed on echocardiographic examination in $69(68 \%)$ patients, mild in 32 (31\%) patients, and moderate in one patient.

No intracardiac thrombi were detected in our patients from the transthoracic approach during the study. Three patients, however, had had a cerebral thromboembolic event postoperatively but more than five years before the study. Two patients had an embolisation 13 and 16 months after TCPC from the site of the blind pulmonary artery stump. Both children underwent repeat operation and their pulmonary

Table 2 Comparison of coagulation factors between patients after total cavopulmonary connection (TCPC) and the control groups

\begin{tabular}{|c|c|c|c|c|c|c|}
\hline & \multicolumn{2}{|l|}{ Children } & \multirow[b]{2}{*}{ p Value } & \multicolumn{2}{|l|}{ Young adults } & \multirow[b]{2}{*}{$\mathrm{p}$ Value } \\
\hline & TCPC $(n=78)$ & Control $(n=37)$ & & TCPC $(n=24)$ & Control $(n=18)$ & \\
\hline Age (years) & $8.8(2.8)$ & $9.4(3.1)$ & NS & $18.4(2.5)$ & $20.1(5.4)$ & NS \\
\hline APTT ratio & $1.06(0.08)$ & $1.05(0.12)$ & NS & $1.02(0.08)$ & $1.02(0.08)$ & NS \\
\hline INR & $1.13(0.09)$ & $1.05(0.07)$ & $<0.001$ & $1.10(0.09)$ & 1.03 (0.09) & 0.018 \\
\hline Fibrinogen (g/l) & $2.39(0.47)$ & $2.58(0.34)$ & 0.029 & $2.15(0.43)$ & $2.80(0.59)$ & $<0.001$ \\
\hline Factor V (\%) & $83(18)$ & $106(16)$ & $<0.001$ & $83(25)$ & $108(19)$ & 0.001 \\
\hline Factor VII (\%) & $69(18)$ & $84(18)$ & $<0.001$ & $73(20)$ & $91(15)$ & 0.003 \\
\hline Antithrombin III (\%) & $114(16)$ & $102(11)$ & $<0.001$ & $118(16)$ & $108(11)$ & 0.034 \\
\hline Protein C (\%) & 71 (17) & $98(18)$ & $<0.001$ & $83(20)$ & $98(17)$ & 0.015 \\
\hline
\end{tabular}

Data are mean (SD).

APTT, activated partial thromboplastin time; INR, international normalised ratio; NS, not significant. 

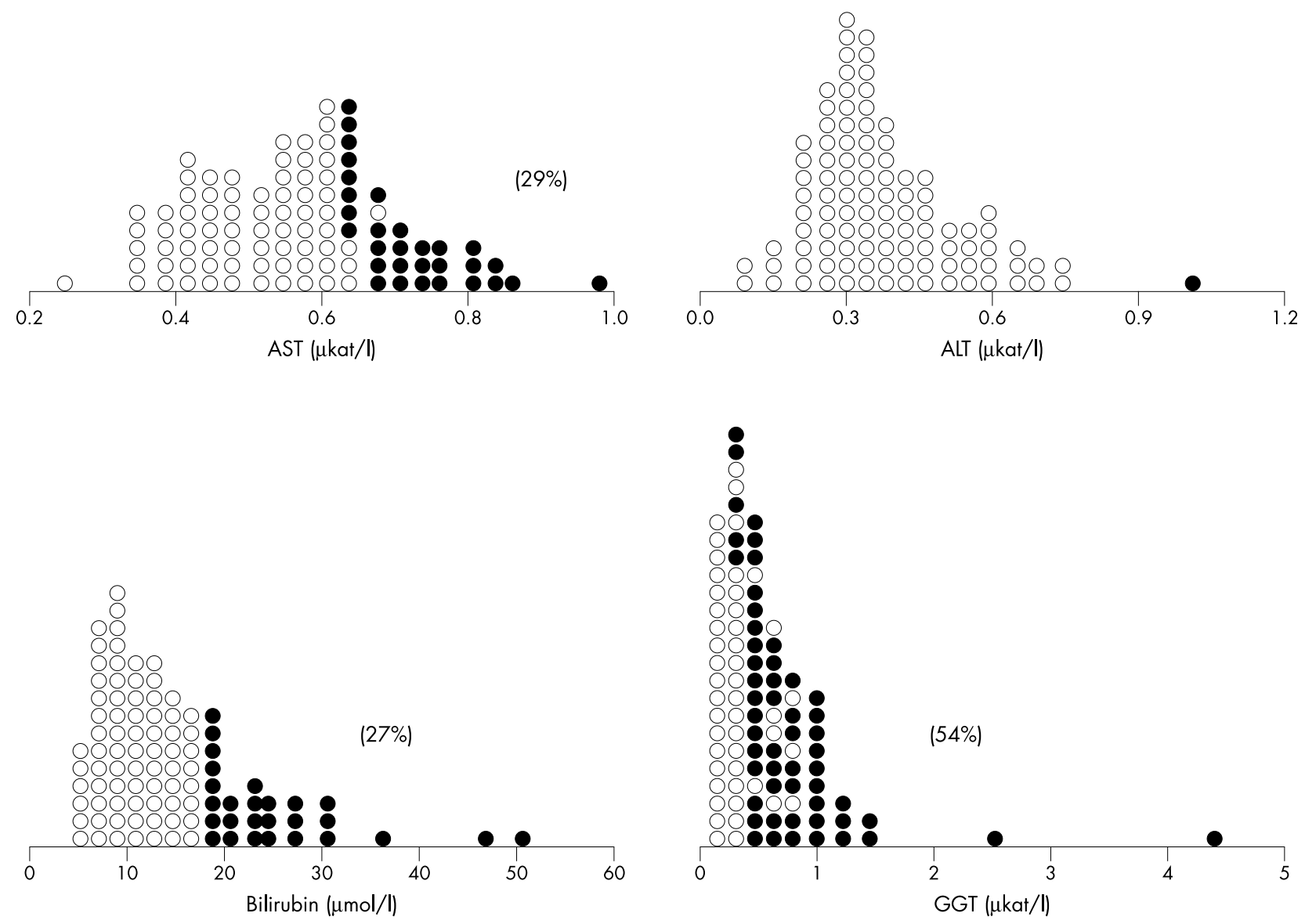

Figure 1 Dot-density plot of the liver tests. Abnormal values ( $Z$ value $>2.0$ or $\leqslant 2.0$ ) are represented by solid circles. The percentages of abnormal values are in parentheses. The overlap of normal and abnormal values is caused by different age related control values. ALT, alanine aminotransferase; AST, aspartate aminotransferase; GGT, $\gamma$ glutamyltransferase.
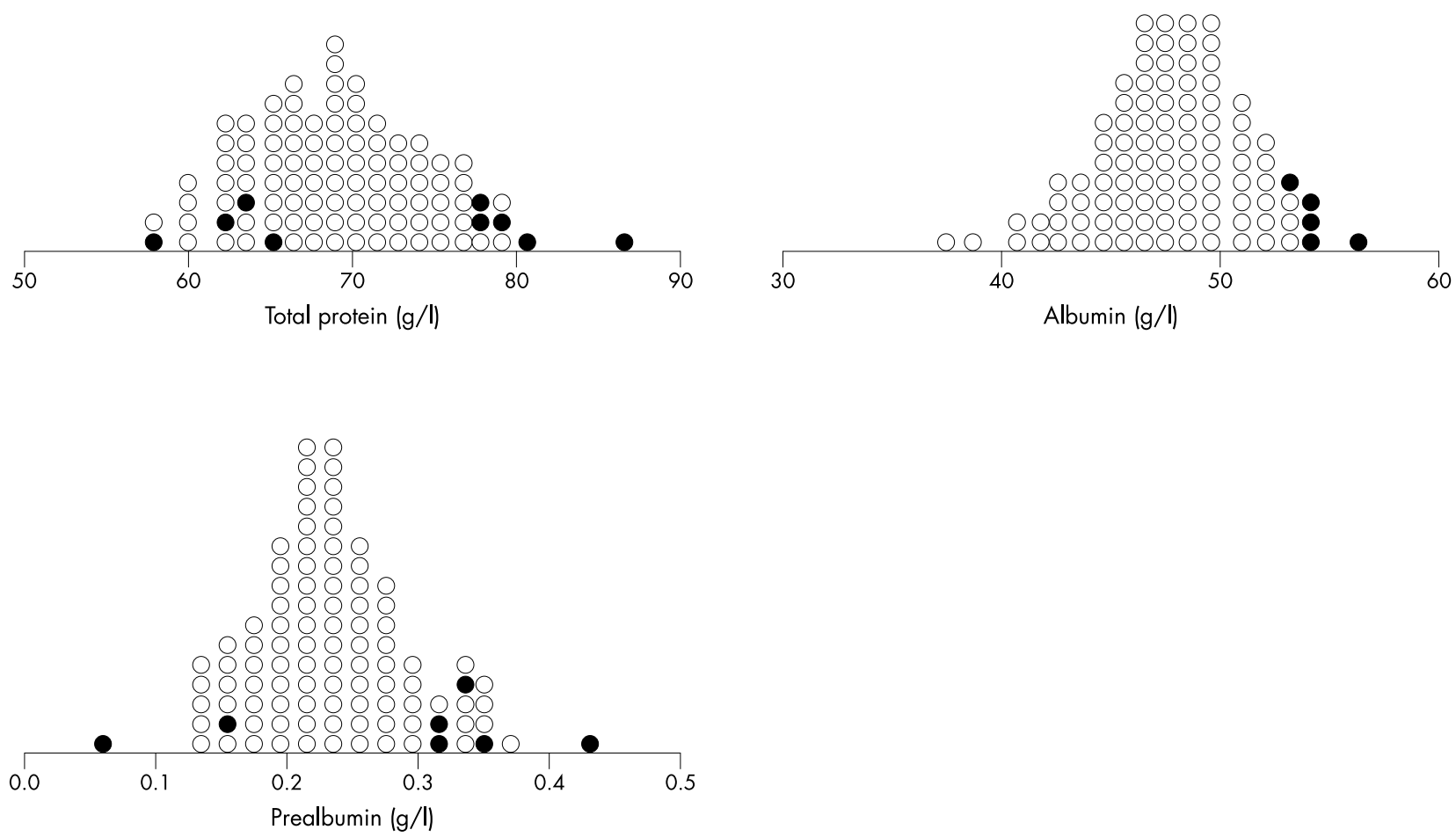

Figure 2 Dot-density plot of serum total protein, albumin, and prealbumin. Abnormal values ( $Z$ value $>2.0$ or $\leqslant 2.0$ ) are represented by solid circles. The overlap of normal and abnormal values is caused by different age related control values. 

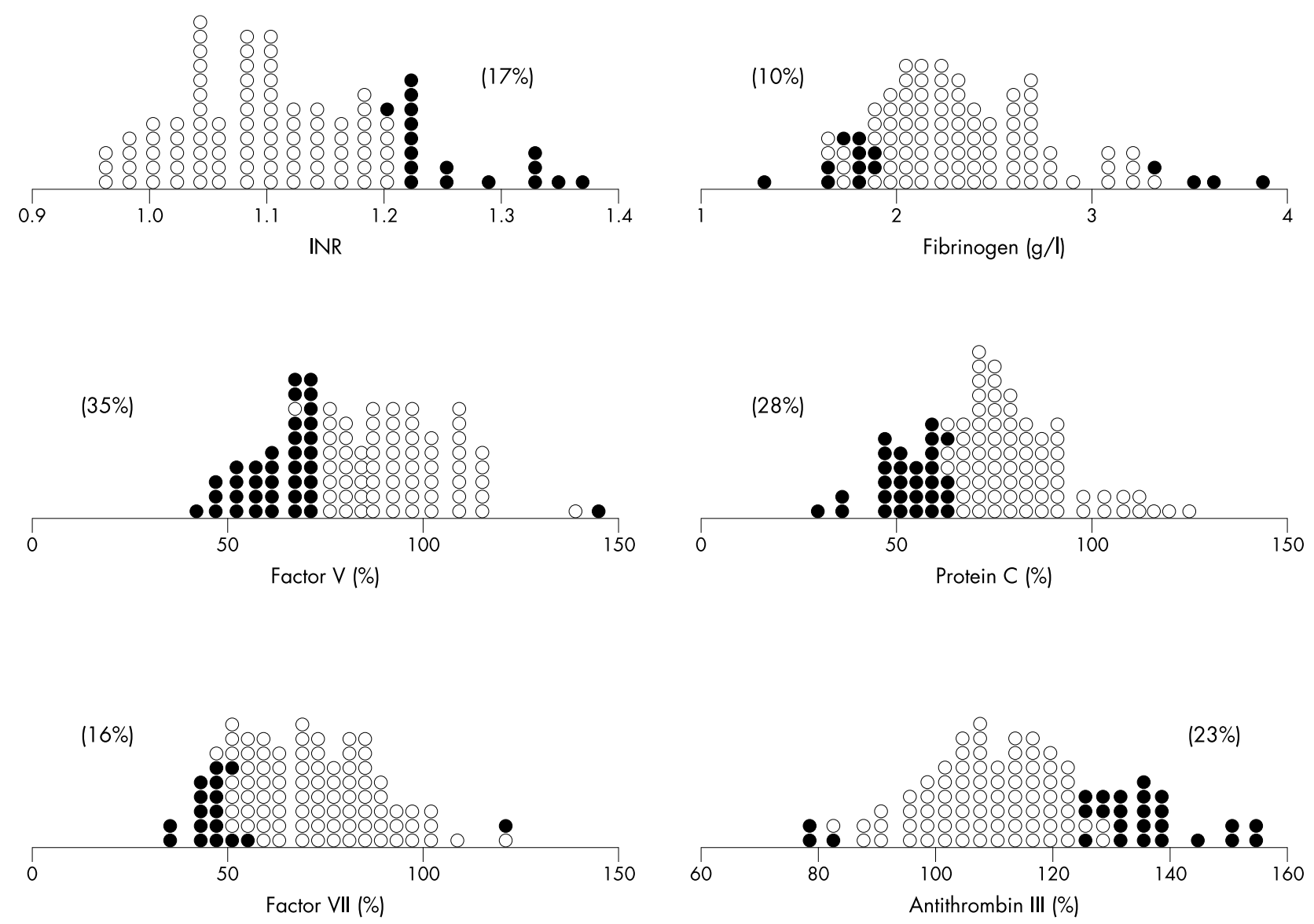

Figure 3 Dot-density plot of the coagulation factors. Abnormal values ( $Z$ value $>2.0$ or $\leqslant 2.0$ ) are represented by solid circles. The percentages of abnormal values are in parentheses. The overlap of normal and abnormal values is caused by different age related control values. INR, international normalised ratio.

artery valve was oversewn surgically. A mild cerebral event occurred in one patient three weeks after TCPC after reopening of a spontaneously closed fenestration. The fenestration was closed with a Rashkind device one year later in this patient.

Table 2 shows the difference in coagulation factors between the patients who had undergone TCPC and the age matched control groups of children and young adults. Compared with the control groups, patients after TCPC had significantly lower fibrinogen, factor $\mathrm{V}$, factor VII, and protein C concentrations, prolonged INR, and increased antithrombin III concentration.

The individual biochemical and coagulation factor data and the percentage of abnormal values $(Z$ value $>2.0$ or $<-2.0$ ) are presented in dot-density graphs. Serum aspartate aminotransferase concentration was abnormally increased in $29 \%$, total bilirubin in $27 \%$, and $\gamma$ glutamyltransferase in $54 \%$ of patients (fig 1).

The serum total protein, albumin, and prealbumin concentrations were normal in most of the patients (fig 2). The mean (SD) serum protein concentration was 69.3 (5.5) g/l (95\% confidence interval (CI) 68.3 to $70.4 \mathrm{~g} / \mathrm{l}$ ), albumin was 47.8 (3.3) g/l (95\% CI 47.2 to $48.5 \mathrm{~g} / \mathrm{l})$, and prealbumin was $0.24(0.06) \mathrm{g} / \mathrm{l}(95 \% \mathrm{CI} 0.22$ to $0.25 \mathrm{~g} / \mathrm{l})$.

INR was abnormally prolonged in $17 \%$ of patients. Factor VII was decreased in $16 \%$, factor V in $35 \%$, and fibrinogen in $10 \%$ of patients (fig 3 ). Protein $\mathrm{C}$ was abnormally reduced in $28 \%$ of patients but antithrombin III was increased in $23 \%$ of patients (fig 3).
The $\mathrm{Z}$ values of procoagulant factors VII and $\mathrm{V}$ and of the anticoagulant factors protein $\mathrm{C}$ and antithrombin III correlated significantly with respect to serum prealbumin (fig 4). There was no relation between the coagulation factors and any of the liver tests.

There was also a relation between procoagulant factor VII and anticoagulant antithrombin III $(r=0.339, \mathrm{p}<0.001)$ or protein $\mathrm{C}(r=0.255, \mathrm{p}=0.010)$ (fig 5). The combined relations between factor VII, protein $\mathrm{C}$, and antithrombin III are displayed in a two dimensional contour plot (fig 6). Most of the patients with low protein $C$ concentration tended also to have decreased factor VII. Interestingly, those patients with decreased protein C and normal factor VII concentrations who could be considered at risk for spontaneous thrombosis had either normal or increased antithrombin III concentration.

The coagulation factors and biochemical variables were not influenced by ventricular function, ventricular morphology, or severity of atrioventricular valve regurgitation. There was also no relation between coagulation factors and arterial oxygen saturation measured by pulse oximetry or between haemoglobin and packed cell volume.

\section{DISCUSSION}

We have observed in patients after TCPC significantly reduced mean concentrations of factor VII, factor V, protein $\mathrm{C}$, and fibrinogen relative to age matched control groups.

Antithrombin III was normal or increased in our patients. A similar profile of the procoagulant and anticoagulant 

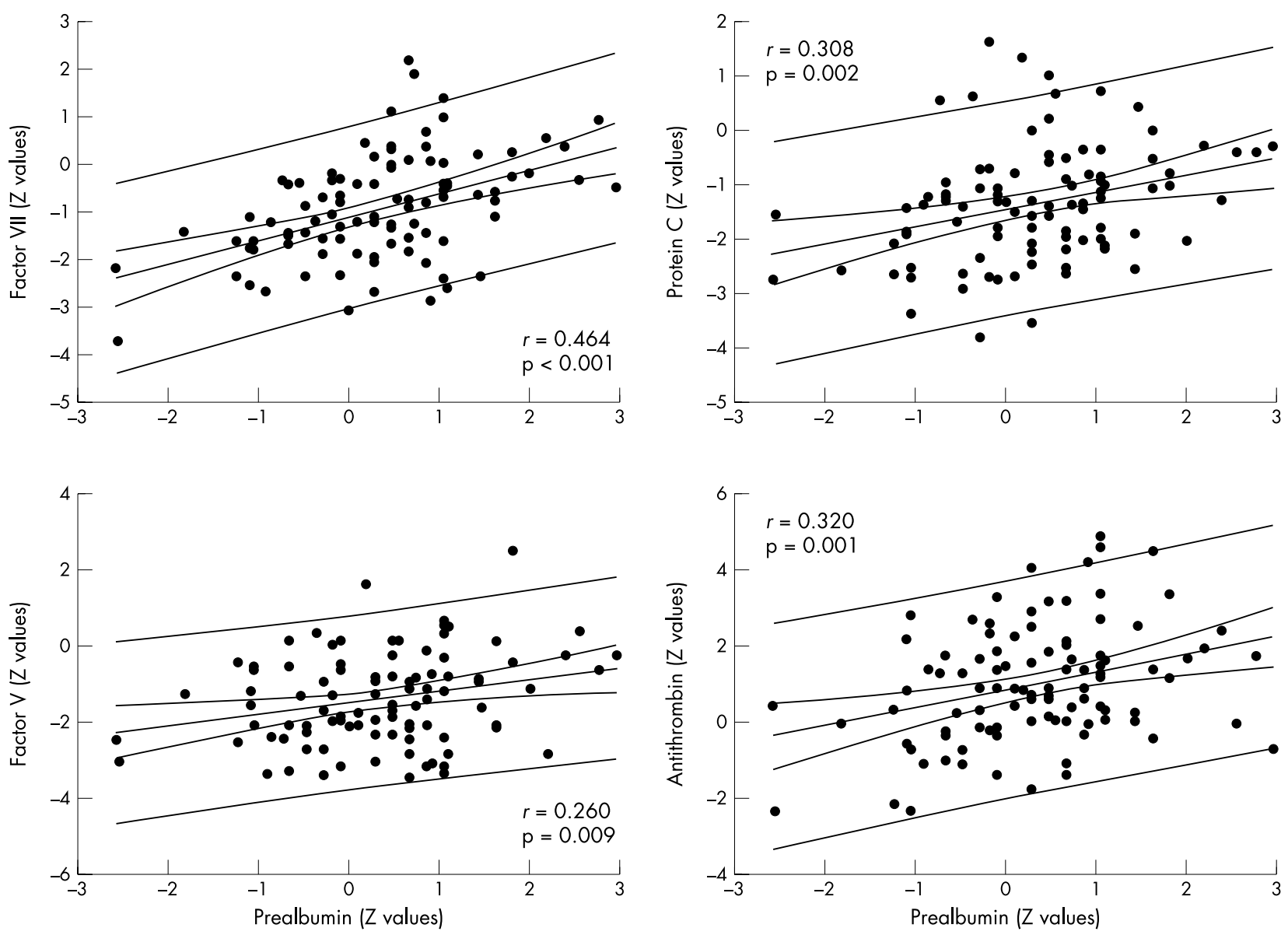

Figure 4 Relation between procoagulant and anticoagulant factors with respect to serum prealbumin. The values were standardised ( $Z$ value) according to age matched control groups. The $95 \%$ confidence and prediction lines are shown.

factors was observed in most studies of patients after the various types of Fontan operation. ${ }^{15-13}$ Some of the studies $^{5} 6910$ were criticised for not considering age related differences in maturation of the coagulation system in the interpretation of their results. ${ }^{15} 16$

The liver is the site of synthesis of all procoagulant and anticoagulant factors with the exception of von Willebrand factor. The synthesis of factors II, VII, IX, and $\mathrm{X}$ and of proteins $\mathrm{C}$ and $\mathrm{S}$ is vitamin $\mathrm{K}$ dependent. ${ }^{17}{ }^{18}$ The direct correlation between age standardised $\mathrm{Z}$ values of procoagulant and anticoagulant factors with respect to serum prealbumin in our study supports the hypothesis that the abnormalities in the coagulation profile observed in patients after Fontan operation are related to protein production in the liver.

We and several other authors have observed the high prevalence of abnormal liver tests, particularly increased concentrations of $\gamma$ glutamyltransferase and bilirubin,
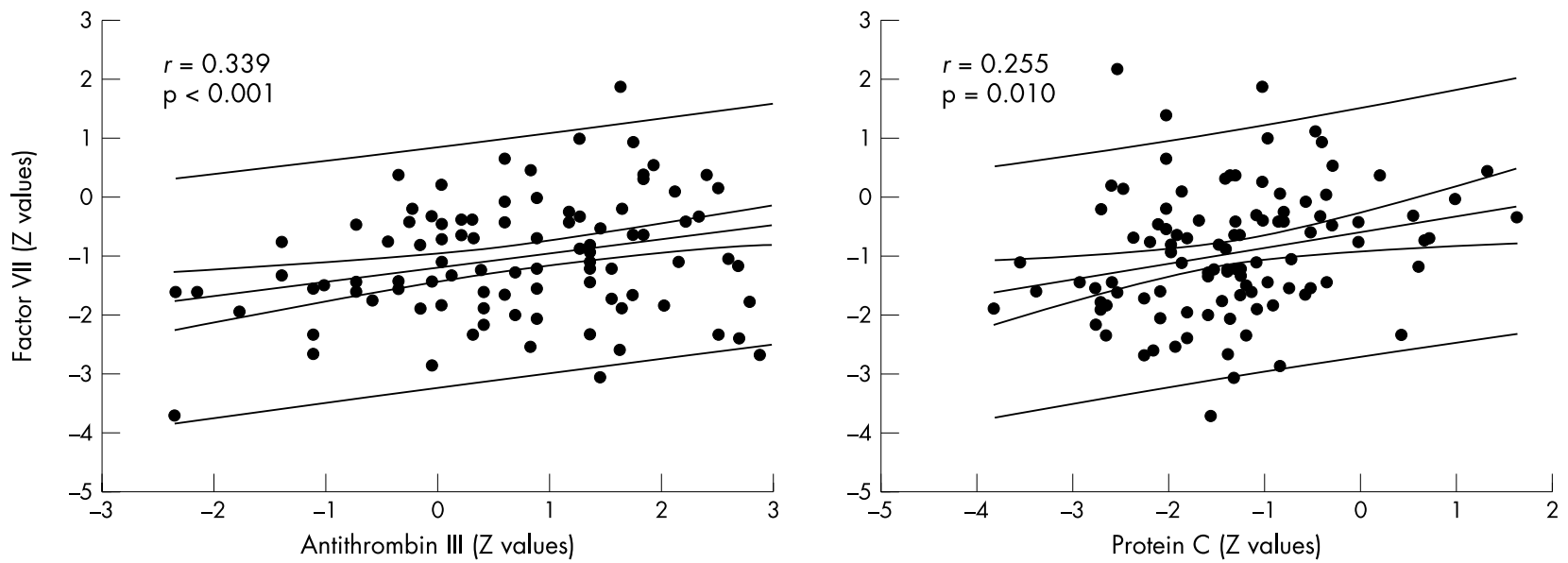

Figure 5 Relation between procoagulant factor VII and anticoagulant factors protein C and antithrombin III. The values were standardised (Z value) according to age matched control groups. The $95 \%$ confidence and prediction lines are shown. 


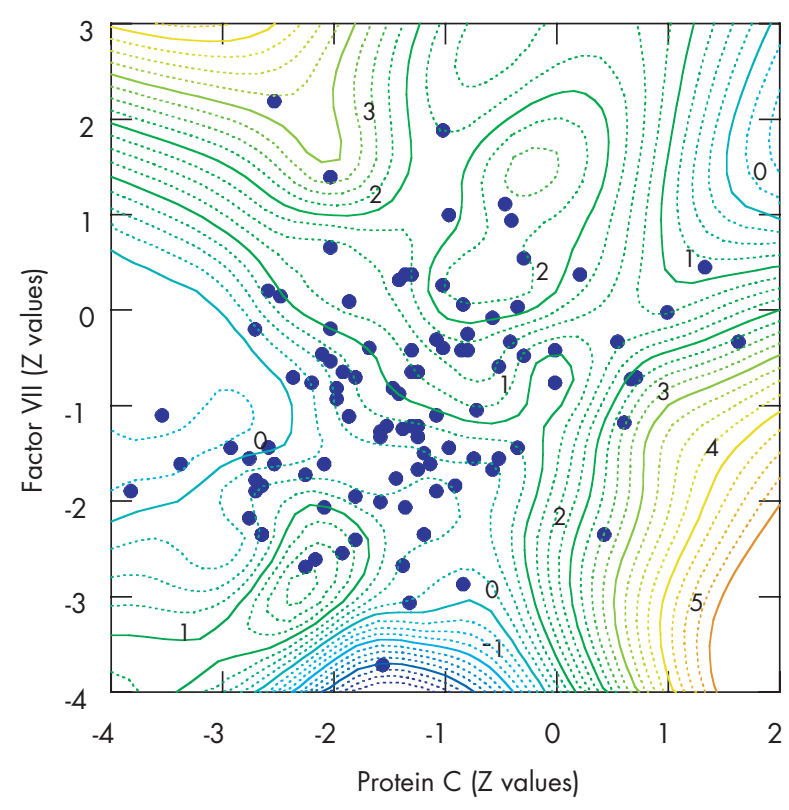

Figure 6 Two dimensional contour graph illustrating the relations between factor VII, protein C, and antithrombin III. The contours of the $z$ axis and the numbers in italics represent the $Z$ values of antithrombin III. All patients with decreased protein C and normal factor VII had either normal or increased antithrombin III concentration.

in up to almost $50 \%$ of patients after the Fontan procedure. $^{15-79}$ 10 $^{13}$ The mild signs of cholestasis with decreased procoagulant and anticoagulant factors synthesised by the liver in patients after the Fontan operations are very similar to those seen in patients with chronic liver disease such as cirrhosis. ${ }^{17} 18$

The overall long term effect of Fontan circulation on liver function is of concern. Recently Narkewicz and colleagues ${ }^{19}$ observed abnormal galactose elimination, as an indirect marker of cardiac cirrhosis, in a small group of children examined on average eight years after the Fontan procedure. In the same study, among four patients who underwent liver biopsy primarily for evaluation for cardiac transplantation, three patients had cirrhosis or extensive liver fibrosis. It was also noted in other studies that patients with cholestasis after the Fontan procedure were significantly older and had longer follow up, ${ }^{7}$ as well as a lower cardiac index and increased central venous pressure. ${ }^{1}$

The risk of spontaneous thrombus formation is increased in patients with Fontan physiology, since some venous blood stasis is always present. In an extensive review, Monagle and colleagues $^{20}$ noted a frequency of thrombotic events ranging from $3-20 \%$ after the Fontan procedures. None of our patient had an intracardiac thrombus detected by the transthoracic echocardiography at the time of study. We are aware that transoesophageal echocardiography is more specific in detecting intracardiac thrombi ${ }^{2021}$; nevertheless, our study protocol did not call for its use because of the need for general anaesthesia in clinically asymptomatic children.

Two patients from the studied group operated on early in our experience had an embolisation from the site of the distally ligated pulmonary artery stump, recognised later as the risk factor for thrombus formation in Fontan patients. ${ }^{22}$ This complication was prevented by subsequent surgical closure of the pulmonary artery valve and both patients are continuing to take only a low dose of aspirin. Echocardiography clearly documented a small thrombus embolising from the site of spontaneously closed fenestration a few days after TCPC in our third patient. The fenestration was closed one year later with a Rashkind device in this particular patient and warfarin was replaced by aspirin six months after the fenestration occlusion.

The possible influence of coagulation factor abnormalities on thromboembolic complications after the Fontan procedure remains unclear. Decreased concentrations of anticoagulant factors $^{5}{ }^{9-11}$ and the recently observed increased concentration of factor VIII $^{911}{ }^{13}$ were regarded as the risk milieu for spontaneous thrombus formation in Fontan patients. We have shown in our large group of patients a direct correlation between the procoagulant factor VII and both anticoagulant protein $C$ and antithrombin III. Interestingly, a few patients with low protein $\mathrm{C}$ and normal factor VII concentrations who could be considered at risk for spontaneous thrombosis always had normal or increased antithrombin III concentration. Normal concentrations of antithrombin III, in contrast to protein $\mathrm{C}$ vitamin $\mathrm{K}$ independent anticoagulant factor, were reported in most coagulation studies of Fontan patients $^{17910}$ but Odegard and colleagues ${ }^{13}$ also noted decreased antithrombin III. Our findings support the view that, although coagulation factor abnormalities are often present, the overall coagulation balance is preserved at mid term follow up after TCPC.

The cause of the coagulation factor abnormalities observed in patients followed up after the Fontan procedure is still unknown. Longstanding increased systemic venous pressure, known to be detrimental to liver function in children and adults with various cardiac diseases, ${ }^{3}{ }^{4}$ is probably just one of the factors influencing liver function in patients after the Fontan procedure. Coagulation factor abnormalities were observed in patients after bidirectional cavopulmonary anastomosis with presumably low splanchnic venous pressure, ${ }^{12}{ }^{23}$ but also in patients with single ventricle physiology before the bidirectional cavopulmonary anastomosis. ${ }^{24}$ No relation between haemodynamic variables and coagulation factors was confirmed in studies of patients after the Fontan procedure, ${ }^{15} 12$ except in a study by Tomita and colleagues ${ }^{8}$ in which protein $\mathrm{C}$ and prothrombin time correlated with right atrial pressure. ${ }^{8}$ Recently a higher superior vena cava pressure was found to be a strong predictor of an increased factor VIII concentration in 13 patients followed up after the Fontan operation, ${ }^{13}$ but factor VIII is produced by liver sinusoidal endothelium and the kidney rather than by the hepatocytes. ${ }^{25}$

We cannot exclude the possibility that the low concentrations of the procoagulant and anticoagulant factors observed in some of our patients were caused by subclinical form of protein losing enteropathy. However, all our patients had serum albumin well above $30 \mathrm{~g} / \mathrm{l}$ and serum protein above $50 \mathrm{~g} / \mathrm{l}$; thus, they did not fulfil the accepted laboratory criteria for clinically important protein losing enteropathy. ${ }^{26}$

\section{Limitations of the study}

The good clinical outcome of the majority of our patients was apparently influenced by the exclusion of patients who were taking warfarin. According to our institutional policy a fenestrated TCPC is performed only in patients with some preoperative risk factors. Patients with fenestrated TCPC are given warfarin until the fenestration is closed spontaneously or surgically and at least six months after the transcatheter occlusion. Other indications for warfarin are poor haemodynamic function, a large pulmonary artery stump, and a previous thromboembolic event. All other patients after TCPC continue taking a prophylactic low dose of aspirin. Our results therefore constitute the coagulation profile in a subpopulation of Fontan patients in good clinical condition who may be at lower risk of thromboembolism.

Cardiac catheterisation was not a part of our outpatient study protocol and therefore we could not investigate the 
relation between coagulation abnormalities and liver tests with respect to haemodynamic data.

\section{Conclusion}

We have documented that almost half the patients after TCPC had laboratory signs of a mild cholestasis. Decreased liver synthesis of procoagulant and anticoagulant factors was observed but overall coagulation homeostasis appeared to be in balance in this selected group of patients with a good clinical outcome.

\section{ACKNOWLEDGEMENTS}

We thank Dr Michael Dewar of Yale University School of Medicine for his comments and reviewing the manuscript. The study was supported by the Grant Agency of The Czech Ministry of Health, No NA5968-3 and No 64203/6092.

\section{Authors' affiliations}

V Chaloupecký, I Svobodová, V Tomek, B Hučín, T Tláskal, J Janoušek, O Reich, J Škovránek, Kardiocentrum, University Hospital Motol, Prague, Czech Republic

I Hadačová, Department of Clinical Haematology, University Hospital Motol

\section{REFERENCES}

1 Kaulitz R, Luhmer I, Bergmann F, et al. Sequelae after modified Fontan operation: postoperative haemodynamic data and organ function. Heart 1997:78:154-9.

2 Stamm C, Friehs I, Mayer JE Jr, et al. Long-term results of the lateral tunnel Fontan operation. J Thorac Cardiovasc Surg 2001;121:28-41.

3 Naschitz JE, Slobodin G, Lewis RJ, et al. Heart diseases affecting the liver and liver diseases affecting the heart. Am Heart J 2000;140:111-20.

4 Mace S, Borkat G, Liebman J. Hepatic dysfunction and cardiovascular abnormalities: occurrence in infants, children, and young adults. Am J Dis Child 1985; 139:60-5.

5 Cromme-Dijkhuis AH, Hess J, Hahlen K, et al. Specific sequelae after Fontan operation at mid- and long-term follow-up. J Thorac Cardiovasc Surg 1993;106:1126-32.

6 Cromme-Dijkhuis AH, Henkens CM, Bijleveld CM, et al. Coagulation factor abnormalities as possible thrombotic risk factors after Fontan operations. Lancet 1990;336:1087-90.

7 van Nieuwenhuizen RC, Peters $M$, Lubbers $\sqcup$, et al. Abnormalities in liver function and coagulation profile following the Fontan procedure. Heart 1999;82:40-6.
8 Tomita H, Yamada O, Ohuchi H, et al. Coagulation profile, hepatic function, and hemodynamics following Fontan-type operations. Cardiol Young $2001 ; 11: 62-6$.

9 Rauch R, Ries M, Hofbeck M, et al. Hemostatic changes following the modified Fontan operation (total cavopulmonary connection). Thromb Haemost 2000;83:678-82

10 Jahangiri $M$, Shore D, Kakkar V, et al. Coagulation factor abnormalities after the Fontan procedure and its modifications. J Thorac Cardiovasc Surg 1997; 113:989-92.

11 Jahangiri M, Kreutzer J, Zurakowski D, et al. Evaluation of hemostatic and coagulation factor abnormalities in patients undergoing the Fontan operation. J Thorac Cardiovasc Surg 2000;120:778-82.

12 Ravn HB, Hjortdal VE, Stenbog EV, et al. Increased platelet reactivity and significant changes in coagulation markers after cavopulmonary connection. Heart 2001;85:61-5

13 Odegard KC, McGowan FX Jr, Zurakowski D, et al. Procoagulant and anticoagulant factor abnormalities following the Fontan procedure: increased factor VIII may predispose to thrombosis. J Thorac Cardiovasc Surg 2003; 125:1260-7.

14 Andrew M, Vegh P, Johnston M. Maturation of the hemostatic system during childhood. Blood 1992;80:1998-2005.

15 Monagle P, Andrew M. Coagulation abnormalities after Fontan procedures. $J$ Thorac Cardiovasc Surg 1998;115:732-3.

16 Barnes C, Monagle P. Haemostatic changes following the modified Fontan procedure. Thromb Haemost 2001;86:1341-2.

17 Martinez J, Barsigian C. Coagulopathy of liver failure and vitamin $\mathrm{K}$ deficiency. In: Loscalzo J, Schafer Al, eds. Thrombosis and hemorrhage. Baltimore: Williams \& Wilkins, 1998:987-1004.

18 Amitrano L, Guardascione MA, Brancaccio V, et al. Coagulation disorders in liver disease. Semin Liver Dis 2002;22:83-96.

19 Narkewicz MR, Sondheimer HM, Ziegler JW, et al. Hepatic dysfunction following the Fontan procedure. J Pediatr Gastroenterol Nutr 2003;36:352-7.

20 Monagle P, Cochrane A, McCrindle B, et al. Thromboembolic complications after Fontan procedures: the role of prophylactic anticoagulation. J Thorac Cardiovasc Surg 1998; 115:493-8.

21 Balling $\mathbf{G}$, Vogt $M$, Kaemmerer $\mathrm{H}$, et al. Intracardiac thrombus formation after the Fontan operation. J Thorac Cardiovasc Surg 2000;119:745-52.

22 Rosenthal DN, Bulbul ZR, Friedman AH, et al. Thrombosis of the pulmonary artery stump after distal ligation. J Thorac Cardiovasc Surg 1995; 110:1563-5.

23 Odegard KC, McGowan FX Jr, Zurakowski D, et al. Coagulation factor abnormalities in patients with single-ventricle physiology immediately prior to the Fontan procedure. Ann Thorac Surg 2002;73:1770-7.

24 Odegard KC, McGowan FX Jr, DiNardo JA, et al. Coagulation abnormalities in patients with single-ventricle physiology precede the Fontan procedure. J Thorac Cardiovasc Surg 2002;123:459-65.

25 Hollestelle MJ, Thinnes T, Crain K, et al. Tissue distribution of factor VIII gene expression in vivo: a closer look. Thromb Haemost 2001;86:855-61.

26 Rychik J, Gui-Yang S. Relation of mesenteric vascular resistance after Fontan operation and protein-losing enteropathy. Am J Cardiol 2002;90:672-4.

\section{ELECTRONIC PAGES}

\section{Heart Online case reports: www.heartjnl.com}

$\square$ he following electronic only articles are published in conjunction with this issue of Heart.

\section{Apical myocardial injury caused by collateralisation of a septal artery during ethanol septal ablation S C Agarwal, I F Purcell, S S Furniss}

In patients who are refractory to medical treatment of hypertrophic cardiomyopathy, surgical myomectomy or percutaneous transluminal alcohol septal myocardial ablation (PTSMA) is appropriate, with both the procedures having comparable results. In PTSMA ethanol is selectively injected into septal arteries supplying the hypertrophied septal myocardium. The authors describe a case of apical myocardial injury caused by passage of ethanol into the distal left anterior descending artery through a septal collateral that developed after double bolus injection of ethanol. They advocate single bolus injection of alcohol to avoid this complication.

(Heart 2005;91:e2) www.heartjnl.com/cgi/content/full/91/l/e2

\section{Moderate mitral stenosis in pregnancy: the haemodynamic impact of diuresis} A Siva, A M Shah

A case of asymptomatic, newly diagnosed, moderate mitral stenosis in a 27 year old pregnant woman is described. A conservative management strategy with regular cardiac assessment was adopted and the patient remained well. Routine transthoracic echocardiography at 36 weeks' gestation showed the development of severe pulmonary hypertension with right ventricular pressure overload, which was successfully treated with oral diuretics resulting in rapid normalisation of pulmonary pressure. Mitral stenosis in pregnancy and its management in pregnancy are briefly discussed.

(Heart 2005;91:e3) www.heartjnl.com/cgi/content/full/91/1/e3 